\title{
Noticias y política en diarios sudamericanos. El tratamiento noticioso del rol de UNASUR en Venezuela (marzo de 2014)
}

Recibido: 01 de octubre de 2014

Aceptado: 26 de mayo de 2015

Publicado: 30 de octubre de 2015

\author{
María Alaniz \\ esmeria75@hotmail.com
}

Universidad Nacional de Córdoba (Argentina)

Resumen: El texto presenta el tratamiento informativo que la prensa escrita realizó en torno al papel de la Unión de Naciones Suramericanas (UNASUR) ante el conflicto sociopolítico venezolano en marzo de 2014. Se caracteriza la UNASUR y su constitución como organismo que fortalece los lazos de integración regional. Luego, se considera el rol de los medios informativos en la visibilización de temas relevantes para la sociedad y la configuración de percepciones y sentidos otorgados a los mismos. En este sentido, se analizan los criterios noticiosos de los diarios El Universal (Venezuela), El Tiempo (Colombia), El Comercio (Ecuador) y El Peruano (Perú).

Palabras claves: Prensa gráfica, criterios de noticias, UNASUR, crisis en Venezuela.

Abstract: The text presents the informative treatment of the regional press regarding statements and the role of the Union of South American Nations (USAN) in the socio-political conflict occurring in Venezuela in March 2014. First and foremost USAN and its creation as an organism which strengthens regional integration bonds are described. Thereafter, considering the media role in making important matters visible for the society and the configuration of perceptions and senses given to them news criteria used in the following newspapers are being analyzed: El Universal (Venezuela), El Tiempo (Colombia), El Comercio (Ecuador) and El Peruano (Peru).

Key words: Press, News Criteria, USAN, Venezuelan crisis. 


\section{Introducción}

América Latina renueva, hacia fines de los ochenta, las iniciativas de integración regional en un escenario caracterizado por el reestablecimiento de los regímenes democráticos y el signo de la economía neoliberal. En este marco, el Mercado Común del Sur (MERCOSUR) sintetiza el proyecto de construcción de un núcleo integrado de poder para afrontar los desafíos de la economía globalizada y el afianzamiento de los procesos democráticos en Sudamérica. El inicio de la fase de integración regional comprende medidas conducentes a la supresión de algunas formas de discriminación económica, como por ejemplo la eliminación de barreras al comercio. En un primer momento, se aspira a una convergencia (fundada en la interdependencia entre dos o más Estados) sobre un plan de acción común en aspectos primero económicos, pero ampliados en el tiempo a la política y la cultura (Alaniz, 2012).

Desde su constitución, MERCOSUR desempeña un rol marcadamente comercial, con momentos de zozobra a lo largo de la década del noventa. Las posibilidades de su recuperación como bloque activo y de proyección estratégica se retoman iniciado el siglo XXI al calor de una agenda regional de temas, propuesta centralmente por los expresidentes Hugo Chávez (Venezuela), Luiz Ignacio "Lula” Da Silva (Brasil) y Néstor Kirchner (Argentina). Se percibe un impulso a las iniciativas de integración política sudamericana, hecho que cobra mayor vigor en la medida que se cierran las puertas para la constitución del Acuerdo de Libre Comercio para las Américas (ALCA) en la IV Cumbre de las Américas en noviembre de 2005.

A partir de allí, el debate sobre modelos de integración en el cono sur se resignifica: no solo atañe a los mandatarios, economistas o cancilleres, sino que también involucra a movimientos sociales, foros contra-globalizadores y otras organizaciones populares que se expresan a favor de una mayor unidad en el continente. La llegada de la Unión de Naciones Suramericanas (UNASUR) se inserta en ese contexto. Desde su creación, goza de acuerdo regional que se ha visto potenciado por la intervención satisfactoria en asuntos regionales. En ese sentido, UNASUR fortalece su rol como entidad garante de soberanía e independencia de los gobiernos en América del Sur.

\section{Objetivos}

El presente trabajo tiene como objetivo general abordar las características del tratamiento informativo de la prensa sudamericana con respecto de las acciones de la UNASUR en su intermediación en el conflicto político-social desarrollado en Venezuela, que se inicia el 12 de febrero de 2014 con movilizaciones y protestas contrarias al gobierno de Nicolás Maduro. Otra finalidad es presentar un análisis del contenido de las noticias y los criterios que emplean los periódicos para la difusión del proceso bolivariano a un año de la muerte de Hugo Chávez. Finalmente, el objetivo es reconocer las modalidades de construcción de lo político en los diarios en el contexto sudamericano. 


\section{Metodología}

La metodología abarca tres momentos o pasos. El primero consiste en la selección de las ediciones digitales de cuatro diarios de América del Sur, a fin de describir el modo y presentación de las noticias políticas en el contexto de la situación social venezolana producto de movilizaciones y enfrentamientos conflictivos entre partidarios y simpatizantes del gobierno de Nicolás Maduro (que conforman un arco "oficialista" o "chavista") y los manifestantes de la oposición, nucleada en la Mesa de Unidad Democrática (MUD) a un año del fallecimiento del ex presidente Hugo Chávez. En ese marco, el papel de los cancilleres y la comisión de UNASUR constituyen las informaciones escogidas.

El segundo paso ha sido relevar las ediciones digitales de la sección "Mundo", de El Tiempo (Colombia); la sección "Mundo", de El Comercio (Ecuador); la sección "Nacional y Política", de El Universal (Venezuela); y la sección "Mundo" de El Peruano (Perú), corpus de un total de diecisiete noticias ${ }^{1}$ escogidas en dos momentos: la reunión de la comisión de cancilleres en Santiago de Chile (11-13/III/2014), en el marco de la asunción de Michelle Bachelet como presidente de Chile; y la visita de dicha comisión a Venezuela (25-27/ III/2014). Se toman los textos informativos en tanto "relatos de los hechos, que evitan descripciones secundarias y secuencias laterales, y recurre a estrategias de legitimación, como la referencia a fuentes oficiales o jerarquizadas que permiten al lector el anclaje de la credibilidad" (Martini, 2000: 110). En ese sentido, el siguiente cuadro (figura 1) ilustra los titulares, fechas, autores, secciones y medios escogidos.

\footnotetext{
1. Cabe puntualizar breves consideraciones sobre los medios escogidos. El Tiempo es un diario colombiano fundado el 30 de enero de 1911 por Alfonso Villegas Restrepo. En la actualidad, es el de mayor circulación en dicho país y por 7 años prácticamente el único nacional, debido a la crisis de su principal competidor ( $E l$ Espectador) que en 2001 se convirtió en semanario antes de volver a ser diario en 2008. El Comercio es un diario ecuatoriano fundado el 1 de enero de 1906 por los hermanos Mantilla Jácome y publicado en la ciudad de Quito. Es el más grande de la ciudad y uno de los más importantes del país. El Universal es un periódico de circulación matutina de Venezuela, fundado el 1 de abril de 1909 por el poeta Andrés Mata y uno de los de mayor tirada del país. Por último, El Peruano es el diario oficial del Perú desde 1825. Además de contar con un cuerpo noticioso y suplementos, incluye las leyes promulgadas, los actos, gastos y nombramientos del Estado.
} 
Figura 1: Relación de textos periodísticos escogidos.

\begin{tabular}{|c|c|c|c|c|}
\hline TÍTULO & DIARIO & SECCIÓN & AUTOR & FECHA \\
\hline $\begin{array}{l}\text { "UNASUR conformará comisión para } \\
\text { analizar situación en Venezuela" }\end{array}$ & El Tiempo & "Mundo" & AFP & $11 / \mathrm{III} / 2014$ \\
\hline "UNASUR analizará caso Venezuela" & El Peruano & "Mundo" & AFP & $12 / \mathrm{III} / 2014$ \\
\hline $\begin{array}{l}\text { "Empezó la reunión de UNASUR para } \\
\text { analizar situación de Venezuela" }\end{array}$ & El Comercio & "Mundo" & No figura & $12 / \mathrm{III} / 2014$ \\
\hline $\begin{array}{l}\text { ¿Qué puede pasar en Venezuela tras un } \\
\text { mes de protestas contra Maduro?" }\end{array}$ & El Tiempo & "Mundo" & Reuters & $12 / \mathrm{III} / 2014$ \\
\hline $\begin{array}{l}\text { "Tema de Venezuela, presente en la } \\
\text { posesión de Bachelet" }\end{array}$ & El Tiempo & "Mundo" & Reuters & $12 / \mathrm{III} / 2014$ \\
\hline $\begin{array}{l}\text { "Oposición venezolana insiste en cinco } \\
\text { condiciones para dialogar con Maduro" }\end{array}$ & El Comercio & "Mundo" & No figura & $13 / \mathrm{III} / 2014$ \\
\hline $\begin{array}{l}\text { "Maduro anuncia la detención de tres } \\
\text { generales que pretendían 'alzarse"” }\end{array}$ & El Tiempo & "Mundo" & EFE & 25/III/2014 \\
\hline $\begin{array}{l}\text { "Colombia y Paraguay piden ampliar } \\
\text { reuniones de UNASUR en Venezuela" }\end{array}$ & El Universal & $\begin{array}{l}\text { "Nacional y } \\
\text { Política" }\end{array}$ & No figura & $25 / \mathrm{III} / 2014$ \\
\hline $\begin{array}{l}\text { "Detienen a tres generales por tramar } \\
\text { 'golpe de Estado' en Venezuela" }\end{array}$ & El Comercio & "Mundo" & No figura & $25 / \mathrm{III} / 2014$ \\
\hline $\begin{array}{l}\text { "María Corina Machado teme ser detenida } \\
\text { en Venezuela" }\end{array}$ & El Comercio & "Mundo" & No figura & $25 / \mathrm{III} / 2014$ \\
\hline $\begin{array}{l}\text { "Fuerza Armada Venezolana no revela } \\
\text { identidad de generales detenidos" }\end{array}$ & El Tiempo & "Mundo" & AFP & 26/III/2014 \\
\hline $\begin{array}{l}\text { "Cancilleres de UNASUR hicieron } \\
\text { recomendaciones a Maduro" }\end{array}$ & El Universal & $\begin{array}{l}\text { "Nacional y } \\
\text { Política" }\end{array}$ & No figura & $26 / \mathrm{III} / 2014$ \\
\hline $\begin{array}{l}\text { "Oposición planteó a UNASUR el tema de } \\
\text { los derechos humanos en el país" }\end{array}$ & El Universal & $\begin{array}{l}\text { "Nacional y } \\
\text { Política" }\end{array}$ & No figura & 26/III/2014 \\
\hline $\begin{array}{l}\text { "Ricardo Patiño ve posibilidades de } \\
\text { solución en conflicto de Venezuela" }\end{array}$ & El Comercio & "Mundo" & No figura & 26/III/2014 \\
\hline $\begin{array}{l}\text { "Comunicado de la I Reunión de la } \\
\text { Comisión de Cancilleres de UNASUR" }\end{array}$ & El Universal & $\begin{array}{l}\text { "Nacional y } \\
\text { Política" }\end{array}$ & No figura & 27/III/2014 \\
\hline $\begin{array}{l}\text { "Venezuela rechaza palabras de EE. UU. } \\
\text { sobre la Comisión de Unasur" }\end{array}$ & El Universal & $\begin{array}{l}\text { "Nacional y } \\
\text { Política" }\end{array}$ & No figura & 27/III/2014 \\
\hline $\begin{array}{l}\text { "Comisión de UNASUR pide compromiso } \\
\text { en deponer la violencia en Venezuela" }\end{array}$ & El Comercio & "Mundo" & No figura & 27/III/2014 \\
\hline
\end{tabular}

Fuente: Elaboración propia. 


\section{La Unión de Naciones Suramericanas}

El Tratado Constitutivo de UNASUR deja sentado los países que conforman la entidad. Así, la República Argentina, la República de Bolivia, la República Federativa del Brasil, la República de Colombia, la República de Chile, la República del Ecuador, la República Cooperativa de Guyana, la República del Paraguay, la República del Perú, la República de Suriname, la República Oriental del Uruguay y la República Bolivariana de Venezuela son las integrantes del bloque regional que inicia formalmente en 2008. Luego, en el Preámbulo, se manifiesta que "apoyadas en la historia compartida y solidaria de Nuestras naciones, multiétnicas, plurilingües y multiculturales, que han luchado por la emancipación y la unidad suramericana, honrando el pensamiento de quienes forjaron nuestra dependencia y libertad a favor de esa unión y la construcción de un futuro común". Asimismo, se "afirma la determinación de construir una identidad y ciudadanía suramericanas y desarrollar un espacio regional integrado en lo político, económico, social, cultural, ambiental, energético y de infraestructura, para contribuir al fortalecimiento de la unidad de América Latina y el Caribe" (UNASUR, 2014a: 7).

A partir de ese momento, el accionar de UNASUR ha potenciado su institucionalidad, legitimidad y rol de mediación ante delicadas instancias políticas en países de la Unión sin intervención inmediata de otras potencias extranjeras, como por ejemplo Estados Unidos o los países europeos. Parece entonces constituirse como un poderoso instrumento de integración que responde a una visión del multilateralismo y que apunta a crear un nuevo instrumento de coordinación política entre los países de América del Sur, en torno a cuestiones de infraestructura, finanzas, políticas sociales, energía y defensa. El Tratado incluyó la definición de algunos elementos de su estructura institucional: el Consejo de Jefas y Jefes de Estado y de Gobierno; el Consejo de Ministras y Ministros de Relaciones Exteriores; el Consejo de Delegadas y Delegados; una Secretaría General en Quito, un Parlamento Sudamericano en Cochabamba, planes para crear un Banco Central regional y una moneda única, un pasaporte regional y la propuesta de creación del Consejo Sudamericano de Defensa (Pizarro, 2012). La Presidencia del organismo se ejerce pro tempore sucesivamente por cada uno de los Estados miembros (en orden alfabético) y la Secretaría General es la encargada de ejecutar los mandatos que le confieren los órganos de la UNASUR y de ejercer su representación.

Es importante señalar, asimismo, que el Artículo 14 hace referencia al diálogo político, poniendo el énfasis en que "la concertación política entre los Estados Miembros de UNASUR será un factor de armonía y respeto mutuo que afiance la estabilidad regional y sustente la preservación de los valores democráticos y la promoción de los derechos humanos. Los Estados Miembros reforzarán la práctica de construcción de consensos en lo que se refiere a los temas centrales de la agenda internacional y promoverán iniciativas que afirmen la identidad de la región como un factor dinámico en las relaciones internacionales" (UNASUR, 2014a: 22). Las referencias al diálogo son reconocidas nuevamente en el Artículo 15, al expresar que "UNASUR promoverá iniciativas de diálogo sobre temas de interés regional o internacional y buscará consolidar mecanismos de cooperación con otros grupos regionales, Estados y otras entidades con personalidad jurídica internacional, priorizando 
proyectos en las áreas de energía, financiamiento, infraestructura, políticas sociales, educación y otras a definirse" (ibidem).

La estrategia del UNASUR de enfrentar cualquier turbulencia que amenace la estabilidad regional quedó claramente reflejada con la crisis en Bolivia a fines de 2008 y en el conflicto de las bases norteamericanas en Colombia en 2009. En esa ocasión, se produjo una primera intervención exitosa en los asuntos internos de uno de sus Estados miembros (Pizarro, 2012).

\section{El papel de UNASUR en Venezuela}

A comienzo de 2014, y un año de la desaparición de Hugo Chávez, la economía venezolana acusa una tasa de inflación alta, deuda y desabastecimiento. El gobierno de Nicolás Maduro presenta los hechos como una "guerra económica" oficiada desde los sectores de la "oligarquía" y el empresariado y los miembros de la "oposición". Entre enero y febrero de 2014 los grados de malestar social se aceleran, incluso en las propias filas del chavismo. Más allá de algunas intervenciones y sanciones a empresarios remarcadores de precios y acaparadores de productos, hay más de un interrogante acerca del modelo de liderazgo de Maduro; se espera un reforzamiento de expresiones del poder popular y de las instituciones públicas al servicio del proyecto bolivariano y el pueblo, y se exige la estricta intervención estatal para establecer precios de bienes y servicios. La situación no queda en las meras discusiones de salón, toda vez que la rivalidad entre el chavismo y la oposición toma un rumbo signado por los enfrentamientos callejeros, cuerpo a cuerpo. Las movilizaciones (que comienzan lideradas por sectores estudiantiles críticos al gobierno) suman seguidores en el transcurso de pocas semanas, hasta que (de uno y otro lado) los roces se transforman en colisiones con muertes en su haber. En este marco, la intervención de los cancilleres de la UNASUR y sus declaraciones y presencia en tierra venezolana, generan un efecto mediador en las aguas del gobierno y la oposición.

En efecto, el comunicado de la UNASUR (26/III/2014) plantea que la primera reunión de la comisión de cancilleres (basada en la Resolución 02/2014, adoptada en Santiago de Chile en febrero de 2014) guarda el "objetivo de acompañar, apoyar y asesorar un diálogo político amplio y constructivo en el país”. La comisión fue recibida por el presidente Maduro y "mantuvo reuniones con las Comisiones Política y Económica de la Conferencia Nacional de Paz, donde participaron diputados del partido del gobierno y de partidos de la oposición, y representantes de los sectores productivos y gremios económicos del país".

En otra parte del comunicado se deja sentado que la "Comisión ha registrado la disposición al diálogo de todos los sectores [...] la Comisión ha identificado en sus contactos un firme rechazo de todos los sectores a los lamentables actos recientes de violencia [...] En este sentido, considera que se debe asumir el compromiso de deponer todas las acciones violentas en Venezuela" (El Universal, 2014a). Se menciona que para dar continuidad al proceso de diálogo, las reuniones de la Comisión tendrán lugar en los días venideros, a través de un grupo de Cancilleres, quienes "reafirman su estricto apoyo a la democracia, resaltando la 
voluntad colectiva de UNASUR en apoyar un proceso de diálogo amplio y respetuoso, tomando en consideración la Conferencia Nacional de Paz, y reiteran su condena a cualquier tentativa de ruptura del orden constitucional" (ibídem).

\section{Noticias y criterios de construcción periodística}

Consideramos que el rol que asume la información en la esfera de las democracias sudamericanas es clave. Además de difundir las declaraciones oficiales y gubernamentales en cada país, los medios hacen visibles determinados temas y ejes de la agenda política y social extra fronteras, operando (si se nos permite la expresión) en la configuración de percepciones sociales sobre el curso de la política regional, los desempeños económicos zonales, el alcance de los derechos sociales, los desafíos de la integración zonal, entre otras situaciones y perspectivas que nutren la actualidad informativa sudamericana. En este sentido, nos parece útil recuperar ciertas nociones que hacen posible la construcción de las noticias, en nuestro caso de análisis, las noticias políticas desde la República Bolivariana de Venezuela.

Luchessi (2010) considera que en el nuevo escenario (el de las tecnologías de la información y del florecimiento de las productoras de contenidos y agencias) la noticia se considera una información de interés para la sociedad. Retomando el interesante trabajo de Borrat (1989) sobre el rol político del periódico, la autora nos recuerda que la publicación de la noticia aparece mediada por las acciones de agentes de prensa, voceros oficiales, fuentes primarias, medios y tiene correspondencia con la línea editorial, las acciones participantes de los medios en el conflicto social y las necesidades de marketing de quienes las difunden.

En este punto, concita la atención el proceso de producción de la noticia, en especial del paso de un acontecimiento de la realidad al de noticia social y pública. El pasaje de "acontecimiento" a "noticia" es el resultado de un trabajo de producción que consiste en la aplicación de lo que se conoce como "criterios de noticiabilidad" establecidos por el medio. En este sentido, Martini (2000: 33) define los criterios de noticiabilidad como aquel conjunto de condiciones y valores que se atribuyen a los acontecimientos, en los cuales operan las relaciones entre el medio, los periodistas y la opinión pública. Distingue para ello a la noticia como el acto de divulgar un suceso, "un proceso de construcción periodística de un acontecimiento cuya novedad, imprevisibilidad y efectos futuros sobre la sociedad lo ubican públicamente para su reconocimiento". Los criterios propuestos por la autora son los siguientes:

- La novedad es la marca que define la noticia ya que alude al "índice de la variación en el sistema" (ibídem: 89) y se aprecia en términos de la existencia del hecho como ruptura. La calidad de novedoso parece no necesitar aclaración. Sin embargo, como gran parte de las noticias que son tapa diariamente en los diarios, constituyen series (continúan durante varios días o semanas porque tematizan problemas graves o abiertos que requieren de un desarrollo, producen otros hechos conexos, como son los casos de medidas de gobierno, delitos, juicios o catástrofes naturales) que deben ser alimentadas con información nueva. De lo contrario, desaparece como tal. 
- La originalidad, la imprevisibilidad y el ineditismo "refuerzan la marca de novedad de un hecho, se mensuran en cuanto al énfasis, a la curiosidad que pueda despertar y a la inquietud que provoca en un ámbito social" (ibídem: 90). Un hecho original es más "noticia" porque es más "novedad". Los hechos imprevisibles operan con fuerza en los imaginarios sociales, propician el surgimiento de significaciones asociadas a la inseguridad y la amenaza. Los acontecimientos marcados por la imprevisibilidad no desaparecen fácilmente de las agendas mediáticas, la conmoción que provocan probablemente se resuelva en nuevos acontecimientos.

- La evolución futura de los acontecimientos marca la significatividad que el acontecimiento adquiere y se expresa "en términos de expectativas que genera el hecho en la sociedad, ya sea que se trate de un hecho que debe resolverse, o que tenga un desarrollo secuencial" (ibídem: 91). La posibilidad de permitir la evolución futura de la información se relaciona también con la base de la práctica periodística: una noticia es más "noticia" si se puede seguir construyendo información a partir de ella durante varios días.

- El grado de importancia y de gravedad de un acontecimiento "se mide en varios niveles, y el central es la incidencia sobre la vida de la sociedad, en términos presentes o futuros, y en términos relativos de conmoción" (ibídem: 92). Las noticias nacionales pesan más que las internacionales (en principio), a menos que las internacionales refieran a hechos que comprometen la nación (guerras, embargos, catástrofes ecológicas, amenazas globales). Las locales son más relevantes que las nacionales cuando afectan a un gran número de personas, y tienen consecuencias sobre el futuro de una comunidad (elecciones a intendente, impuesto local, incremento del delito, epidemias).

- La proximidad geográfica de un acontecimiento "se valora en función de los centros de interés del público" (ibídem: 93). La proximidad se enlaza con el efecto sobre lo local y, en el caso de la información televisiva, las imágenes golpean por el reconocimiento posible. Este valor se asocia con la cantidad de las personas implicadas.

- La magnitud por la cantidad de personas o lugares implicados "se evalúa en la potencial implicación del público al que la noticia va dirigida, e implica su gravedad (en términos cualitativos propios del hecho y en términos de los efectos sobre la sociedad, la nación, etc.)" (ibídem: 94).

- La jerarquía de los personajes implicados en un acontecimiento se dimensiona "en función de las apariciones y la presencia pública de personajes conocidos que son siempre noticia" (ibídem). Pero también adquieren valor de noticiabilidad los hechos protagonizados por personajes comunes, que pueden referir a colectivos o grupos cercanos al interés o la simpatía del público.

- La inclusión de desplazamientos se "evalúa tanto si son conjuntos de personas, o individuos públicos reconocidos. Se trata de movimientos o agrupaciones significa- 
tivas, cambios de lugar o de posición, y trayectorias que permiten efectos diversos sobre la sociedad (ibídem: 95). Son útiles para la práctica periodística porque son hechos anunciados, previstos, con una organización detrás; resultan más fácilmente abordables y son adecuados para la televisión, por su carácter visible, notorio y espectacular.

Por último, para los fines del presente trabajo, se han escogido cuatro de los criterios descritos, reagrupados en función de haber considerado que existen similitudes, afinidades conceptuales entre ellos, quedando los mismos del siguiente modo: $a$ ) una primera relación entre la originalidad, el ineditismo, la imprevisibilidad, curiosidad de un acontecimiento, que puede ser reagrupado bajo el criterio novedad; b) el grado de importancia y/o de gravedad de un hecho, la magnitud y el grado de involucramiento de personas, así como la inclusión de desplazamientos que se pueden articular bajo el criterio de significatividad. Por último, los criterios de $c$ ) jerarquía de los personajes y $d$ ) proximidad geográfica, donde también puede incluirse la magnitud en términos de ámbitos geográficos implicados en un acontecimiento.

\section{Resultados del análisis de noticias}

\subsection{La novedad}

Con relación al criterio de novedad (entendido como el hecho que marca ruptura, es inédito e imprevisible) ha de partirse de un acontecimiento que no se menciona explícitamente en las informaciones relevadas, pero que es fuente sustantiva de los enfrentamientos entre manifestantes "chavistas" y la "oposición" (aglutinada en la Mesa de Unidad Democrática, MUD): la muerte de Hugo Chávez (febrero de 2013) abre una etapa de incertidumbre en cuanto al liderazgo del proceso bolivariano y el rumbo del mismo. La desaparición de Chávez descoloca a propios y ajenos, es decir, deja un vacío inmenso para el oficialismo en el gobierno, pero acelera también, los tiempos de armado de la oposición y la búsqueda de un dirigente capaz de aglutinar la disputa por encima de intereses personales.

De allí que la tensa situación social, alimentada por un descalabro en la economía venezolana y la consecuente debilidad de un gobierno "sin el Comandante" pone en foco las protestas venezolanas. No significa que no haya existido malestar con anterioridad (e incluso en vida de Chávez), pero lo cierto es que el cariz de los enfrentamientos se enciende en las calles, con movilizaciones de una y otra parte de un modo que cobra envergadura internacional. La pérdida de Chávez y la "crisis" global abierta desde entonces han potenciado un giro inesperado de la política, una novedad en términos de acontecimiento político, expresada como tal por la prensa continental.

Tan graves son los eventos para los venezolanos, los sudamericanos y los gobiernos de la región, que el segundo punto de novedad es el papel de la UNASUR: reunida primero en Santiago de Chile y luego en Caracas, intercede en el dialogo de las partes de un modo decisivo. Según palabras del Ministro de Relaciones Exteriores de Venezuela, Elías Jaua, "la UNASUR ha salido fortalecida de este amplio debate a favor de los valores democrá- 
ticos [...] Nos sentimos plenamente satisfechos con la resolución [de enviar una comisión de cancilleres a Caracas] nos sentimos acompañados en la batalla que está dando el pueblo venezolano por la democracia, por la paz" (El Universal, 2014g).

Una vez más la organización sudamericana hace su presencia en asuntos internos de la región, desplazando a la OEA, y manifestando la preocupación ante cualquier amenaza a la independencia y soberanía de la República Bolivariana. Se trata de un posicionamiento que fortalece la mirada de unidad frente a cambios de orden institucional abruptos, como lo fueron el caso de Honduras, los intentos de desplazar a Correa en Ecuador y la destitución de Fernando Lugo en Paraguay. En un mismo sentido, el presidente ecuatoriano Rafael Correa señala que le gustaría que la sesión de UNASUR "termine con el apoyo irrestricto al orden constitucional en Venezuela y al gobierno legítimamente electo” (ibídem).

Respecto al tenor de los enfrentamientos, hay marcas de ruptura e imprevisibilidad respecto al espesor de las movilizaciones. Tal es así que Nicolás Maduro afirma que "Caracas está viviendo en paz" y que su Gobierno frenará las marchas que pueda convocar la oposición en la capital de su país, al cumplirse un mes del inicio de las protestas. El presidente hace las declaraciones a la emisora colombiana Blu Radio desde el Palacio de Miraflores en un breve diálogo en el que insiste en que la única salida a la situación que vive su país desde el pasado 12 de febrero es que la oposición cese su "guarimba" (barricadas) y "se siente a una mesa" a negociar. Maduro agrega que "ese esquemita, ese formato" no lo va a permitir e insta al MUD a llamar al orden a los "grupos violentos" que a su juicio la secundan (El Tiempo, 2014c).

También menciona una marcha convocada por estudiantes con intención de ir hacia la Defensoría del Pueblo, y advierte sobre la "situación de violencia" que se vive en la zona fronteriza con Colombia, algo que según dijo, no es nuevo y que achacó a "bandas criminales y paramilitares" colombianas que "están apoyando a la extrema derecha" (ibídem). El diario colombiano da cuenta que "los presidentes ordenaron a sus ministros de Relaciones Exteriores celebrar una reunión mañana (miércoles), para crear una comisión [...] para que el diálogo construya un ambiente de acuerdo, de consenso y de estabilidad allí en Venezuela". En la cita, los cancilleres analizarán los hechos de violencia ocurridos en Venezuela. "Nosotros siempre vamos a procurar mantener el orden democrático”, agregó Rousseff (El Tiempo, 2014e).

En igual sentido se expresa el diario ecuatoriano El Comercio, al citar al canciller chileno Heraldo Muñoz, quien expresa su "deseo de que la UNASUR pueda jugar un papel relevante en la solución de la crisis política venezolana; y esperamos no simplemente tener frutos declarativos sino tener frutos concretos. Nada que afecta a un país hermano nos es ajeno" (El Comercio, 2014f). En otra noticia se informa sobre reuniones entre el Secretario de Estado norteamericano Joe Biden, para tratar el tema de Venezuela con Bachelet, el presidente peruano Ollanta Humala, y el de Colombia, Juan Manuel Santos. Por su parte, el ex mandatario colombiano y ex secretario de la OEA, César Gaviria, expresa que "se están poniendo en grave peligro la libertad de prensa y expresión y el respeto por los derechos humanos en Venezuela" y el Consejo Episcopal Latinoamericano manifiesta que "la herramienta más adecuada es más y mejor democracia y no los atajos autoritarios" (El Tiempo, 2014d). 
La novedad aparece tratada en la información referida a la detención de "los tres generales de la Aviación que pretendían alzar a la Fuerza Aérea contra el Gobierno, que ya están a la orden de los Tribunales Militares del país". Maduro lamenta que los oficiales hayan perdido su carrera "escuchando consejos de quienes quieren destruir la democracia". Los militares están "protegiendo a nuestro pueblo, velando por la soberanía de nuestra patria y respaldando al presidente y comandante en jefe de la FANB constitucionalmente electo", agrega la institución castrense en el comunicado. Pese a las detenciones, el comunicado asegura que "la Fuerza Armada Nacional Bolivariana se mantiene monolítica" y mantiene la “convicción democrática” (El Tiempo, 2014a). Según las expresiones vertidas por El Comercio, "el grupo capturado tiene vínculos con sectores de la oposición [...] enfrentamos un golpe de Estado continuado de opositores a los que acusa [Maduro] de vínculos con países extranjeros, entre ellos EE. UU. y Colombia” (El Comercio, 2014d).

Por su parte, en la prensa peruana hay una mención a la entrada de UNASUR como mediador de la crisis. La idea de una Comisión de UNASUR para tratar el caso venezolano nace en Santiago de Chile con la intención de "que fomente el diálogo en Venezuela, afectada por una ola de protestas a favor y en contra de Nicolás Maduro" (El Peruano, 2014). La defensa del "orden democrático" es la expresión de Dilma Rousseff y avalada por los cancilleres que acuden a la asunción de la mandataria chilena (ibidem). La imagen que acompaña la nota muestra una reunión de UNASUR en lo que se supone es una sesión de trabajo.

\subsection{La significatividad}

Respecto al criterio de significatividad y la evolución futura de los acontecimientos, las informaciones dan cuenta de señales favorables al entendimiento entre gobierno y oposición, producto de la mediación y el rol preponderante de la UNASUR. Se resalta el acuerdo de los cancilleres en lograr el diálogo, hechos que se concretan en la visita del 25 y 26 de marzo; el acercamiento a la oposición, para lo cual se mantienen reuniones con el MUD y especialmente con sus referentes, Ramón Guillermo Aveledo quien expresa que "le hemos dicho a ellos [por los cancilleres] lo mismo que le hemos dicho al país: que estamos siempre como demócratas dispuestos a un dialogo respetuoso. Un diálogo en plano de igualdad, un diálogo que pueda presenciar todo el país" (El Universal, 2014e). En ese sentido, el dirigente del MUD plantea el asunto de "los presos políticos", sin mencionar nombres; y les entrega a los cancilleres un "informe muy detallado en materia de derechos humanos con los detenidos, con las causas abiertas, y un informe en vídeo y en fotografía acerca de las violaciones a derechos humanos acaecidas en la represión de estos días" (ibídem).

Tras el comunicado y las sugerencias que la comisión le eleva a Maduro, se hace pública una declaración que destaca las reuniones con el gobierno, con las comisiones Política y Económica de la Conferencia Nacional de la Paz (conformada por diputados oficialistas y de la oposición y representantes de los sectores productivos y gremiales) y con los lideres que forman el Gran Polo Patriótico (GPP) y la MUD; resaltando que "se ha registrado la disposición al diálogo de todos los sectores, los cuales manifestaron la necesidad de mode- 
rar el lenguaje, generando así un ambiente pacífico que favorezca las conversaciones entre el Gobierno y los distintos actores políticos económicos y sociales del país" (El Universal, 2014a). Se considera en el documento que "se debe asumir el compromiso de deponer todas las acciones violentas en Venezuela" (ibídem). Aquí resulta evidente que en términos de evolución de los acontecimientos, el futuro que se abre en perspectiva de la apertura de Maduro y la viabilidad de instalar una negociación, depara consecuencias no sólo para el desarrollo de las relaciones entre gobierno y oposición sino también, para el conjunto de la sociedad venezolana. Por ello es que, a los quince días de la declaración, Maduro acepta la petición de UNASUR para reunirse con la oposición, con la expectativa de que esta ventana que se abre con el diálogo logre "la ecuación de paz, de la Conferencia de paz que está funcionando en Venezuela y por fin logremos que los factores de oposición se sienten a dialogar para la paz y por la paz" (El Universal, 2014h).

El Comercio de Ecuador, informa sobre las condiciones solicitadas por la oposición para negociar, consideradas "vitales" a saber, la libertad del dirigente Leopoldo López así como el "regreso de los exiliados", "justicia para todas las víctimas de la represión", un "alto al hambre, al racionamiento y a las colas" y poner fin a la inseguridad y a la delincuencia, "en un país con una alta tasa de criminalidad" (El Comercio, 2014e). En la misma información se menciona al líder Henrique Capriles quien señala que está a favor de la paz, pero no formará parte de "la comparsa". "Nicolás te lo he dicho mil veces, no aguantas un debate conmigo! Atiende el caos que creaste!'. Unas semanas después, la diputada opositora María Corina Machado (de viaje por Perú) expresa que "teme ser detenida después que fuera suspendida como legisladora en Venezuela" (El Comercio, 2014c). La noticia agrega que el congresista peruano Martín Belaúnde va a solicitar intervención del Congreso de su país, del Ministerio de Relaciones Exteriores y del propio presidente Ollanta Humala para que oficien "ante las autoridades venezolanas para que se den todas las garantías que corresponden a los diputados" (ibídem).

En otra nota, la significatividad puesta en las posibilidades de solución del conflicto venezolano es tomada por el diario para resaltar las palabras del canciller ecuatoriano, Ricardo Patiño. El ministro reconoce "que hay voluntad de ambas partes" y que en el país hay condiciones para que se produzca "una mayor participación de los actores en los diálogos de paz" y reconoce que hace falta "un puente den el camino" que pueden ser los cancilleres latinoamericanos. Para el futuro y la evolución positiva de las relaciones sociales dentro del país el rol de UNASUR no es el de "pacificar" ni que a la fuerza terminen los focos de violencia" (El Comercio, 2014b), sino propiciar diálogos “fructíferos" para atender problemas como la inseguridad y la inflación.

Un día después, la Comisión de Cancilleres de UNASUR pide “deponer acciones violentas y anuncia nuevas reuniones" (El Comercio, 2014a). En esa instancia lo significativo en función de la evolución futura del conflicto reside en la apuesta de la Comisión que reunida con Maduro y reconociendo su apertura, destaca la "disposición al dialogo, moderar el lenguaje, generando un ambiente pacífico que favorezca las conversaciones entre Gobierno y distintos sectores políticos, económicos y sociales" (ibídem). 


\subsection{Actores}

En cuanto a la jerarquía de los actores involucrados en las noticias relevadas, se observa una preponderancia de personajes institucionales: la UNASUR, como entidad sudamericana; la Comisión de Cancilleres, encabezada por María Ángela Holguín (Colombia), Héctor Timerman (Argentina), David Choquehuanca (Bolivia), Ricardo Patiño (Ecuador), Luis Almagro (Uruguay), Luiz Alberto Figuereido (Brasil) y Alí Rodríguez (Venezuela); los presidentes Michelle Bachelet, Rafael Correa y Dilma Rousseff. Otro actor fundamental del proceso es el mandatario venezolano Nicolás Maduro y, por supuesto, la oposición encabezada por la Mesa de Unidad Democrática, cuya figura principal es Ramón Guillermo Aveledo y alusiones (en menor medida) a Corina Machado, Leopoldo López y Henrique Capriles.

En sintonía con lo mencionado, el principal actor al que se refieren los cuatro periódicos observados es la UNASUR, caracterizada como institución regional y representada por los cancilleres designados para la mediación en el conflicto venezolano. El papel de la UNASUR aparece construido en el hecho noticioso ligado a los conceptos de diálogo, acuerdos, consensos, paz, defensa de la institucionalidad y la democracia. Ello es sustentado por las valoraciones que realizan los presidentes de Chile, Brasil y Ecuador acerca del papel mediador de UNASUR.

Por su parte, en El Universal aparecen la UNASUR y los cancilleres como los actores protagonistas de la información, junto al Presidente Nicolás Maduro. Aquí no hay menciones a los presidentes sudamericanos. En ese sentido, se potencia el papel de la UNASUR como mediador y como organismo encargado de "acompañar, apoyar y asesorar un diálogo político amplio constructivo en el país”. Se jerarquiza la referencia de Ramón Aveledo, Secretario de la MUD, posicionándolo como la voz prácticamente única en lo que se refiere al discurso y liderazgo de la oposición a Maduro. La voz del mandatario venezolano está presente en todos los periódicos relevados.

Lo mismo se repite en el periódico El Comercio, que hace foco en los representantes de "la alianza que conforma la oposición venezolana" como actores centrales de la construcción noticiosa. Citan al MUD y en la información aparecen reflejados los requisitos que este sector reclama al Gobierno Nacional para sentarse a dialogar. En este marco, se citan mensajes de Twitter de Henrique Capriles y Corina Machado. Por su parte, El Tiempo agrega a las citas sobre UNASUR, Maduro y algunos líderes sudamericanos, la mención al Secretario de Estado norteamericano Joe Biden, quien sugiere que no debe haber soluciones impuestas en Venezuela. El Peruano destaca la UNASUR, las declaraciones de Dilma Rousseff y de Nicolás Maduro que es blanco de las protestas en su país.

\subsection{La proximidad geográfica}

La cercanía geográfica no es un dato menor, toda vez que tanto la reunión de Santiago de Chile (para la preparación de la comisión de UNASUR) como la visita a Caracas los colo- 
can en el centro de atención de los mandatarios regionales, del activismo político (a favor o en contra) del gobierno de Maduro; de la prensa continental y, por supuesto, del conjunto de la población venezolana que asiste cotidianamente al escenario de enfrentamiento, escasez económica, tensión en las calles.

Esta caracterización se trasluce, en mayor medida, en la cobertura y presentación que hacen El Universal, El Tiempo y El Peruano al contar, por un lado, la reunión de Santiago de Chile, que cobija a los cancilleres de UNASUR, los cuales (además de tratar el tema Venezuela) acompañan la asunción de la mandataria Michelle Bachelet. Luego, es Caracas la ciudad que acoge el calor de los encuentros entre los cancilleres con el gobierno y la oposición, ciudad que se trasforma de caótica y violenta en el punto de cónclave de "un dialogo para y por la paz". En el diario ecuatoriano, la alusión es indirecta, es decir, se refiere a contar lo acaecido en Caracas, pero sin presencia de periodistas en el lugar de las reuniones.

\section{Conclusiones}

Las noticias analizadas en el presente trabajo dan cuenta de un protagonismo de la UNASUR como actor central del proceso de diálogo y pacificación en torno a la llamada "crisis venezolana". En ninguna de ellas hay remisiones directas a las causalidades de dicha crisis, pero se deja entrever que la misma inestabilidad económica e institucional se debe a la falta de un liderazgo unificador tras la muerte del ex presidente Hugo Chávez.

La geografía que entrecruza los debates y acercamientos propiciados desde UNASUR recorre primero Santiago de Chile, donde las informaciones dan cuenta de la reunión sudamericana en el contexto de asunción de la presidenta Bachelet. Luego, la capital venezolana gana un espacio importante de las informaciones: es en Caracas donde se desarrollan los encuentros, las movilizaciones de uno y otro sector. El presidente Maduro y los voceros del chavismo, por un lado, y la oposición (encabezada por la MUD) por otro, aparecen como figuras destacadas significativamente en las noticias, con alusiones directas, citas y declaraciones de sus principales referentes.

La UNASUR y sus cancilleres son también fuente de significatividad informativa; la mirada de los medios irradia el tenor de la participación de la entidad sudamericana en los asuntos políticos del Cono Sur y en la creación de una agenda propia de discusión y solución. La cobertura de los diarios El Universal, El Tiempo y El Comercio, muestra matices interesantes respecto a la trascendencia que cada uno le otorga al tema. En ese sentido, a través de los criterios con los que construyen las noticias, se significan diversas percepciones y valoraciones sobre la "crisis venezolana" y los alcances de la "unidad sudamericana" en la expresión orgánica de la UNASUR.

El Universal centra su interés en el hecho local, a un año de la muerte de Chávez, y en un escenario volátil en las calles. Por su parte, El Tiempo matiza entre las noticias, las diferencias históricas con el país vecino, los momentos de tensión vividos en las fronteras y la disparidad entre un tipo de gobierno y otro. Con respecto a El Comercio, se destaca (por sobre 
la crisis y la violencia) el valor de la Comisión de Cancilleres y de UNASUR para fomentar la reconciliación y el diálogo. Por su parte, El Peruano tiene una noticia referida a la reunión de UNASUR, con escasa profundidad en el abordaje de los hechos en Venezuela ${ }^{2}$.

El acontecimiento político se presenta como el corolario de una etapa de negociaciones donde los gobiernos asumen el compromiso de recuperar las relaciones de confianza, apostando a la defensa del orden democrático y los gobiernos electos por vía constitucional. Las criterios periodísticos con los cuales se narran los momentos relevantes del proceso de crisis y la mediación de UNASUR exponen los hechos como eventos cercanos al lector (criterio geográfico), apelando a la voluntad de oficialistas y opositores tras meses de enfrentamientos (criterio significatividad), con el centro puesto en la unidad tanto en Venezuela como en el Cono Sur, sostenidos por la acción y la palabra de dirigentes y políticos dispuestos a dar una vuelta de página (los actores).

En definitiva, los criterios agregan valor, un plus simbólico que refuerza la idea de integración regional ante todo, la mediación de un ente sudamericano propio antes que la entrada de referentes extranjeros. En los medios de mayor cobertura hay una construcción noticiosa donde se pone el acento en el protagonismo de la UNASUR a partir del seguimiento del papel que este organismo fue jugando en el conflicto venezolano. Aquí se reconstruye desde una mirada positiva la intervención de UNASUR y se lo liga a los conceptos de "diálogo", "paz", "consensos". A lo largo de las informaciones hay algunos términos que se repiten sistemáticamente y no constituyen meras palabras articuladas en las noticias políticas. Dichos términos fueron "protestas", "crisis económica", "violencia", "enfrentamientos", “inseguridad”, “diálogo”, “oposición”, “paz”, entre los más mencionados.

En El Universal, el diálogo aparece fuertemente unido a la UNASUR, sus representantes y a las expresiones emitidas desde parte del gobierno de Maduro. Son frecuentes las menciones tales como "todas las iniciativas surgidas en los últimos meses son producto de la voluntad de diálogo del Gobierno Nacional", "retomar el diálogo con Estados Unidos sobre la base del respeto mutuo", "diálogo político amplio", en referencia a la UNASUR, como también "diálogo entre todos los sectores". En las noticias, solo hay una mención a declaraciones de Aveledo, quien señala a la oposición "como demócratas dispuestos a un diálogo respetuoso". Asimismo, el término "paz" es fundamentalmente unido a las iniciativas oficialistas. "Me propusieron hacer una reunión [...] y acepté, por la paz, la democracia, por Venezuela", "va a ser un gran mensaje de paz y de democracia para nuestro país", "la lucha que estamos dando por la paz", "por fin logremos que los factores de la oposición se sienten a dialogar para la paz y por la paz", son solo algunos de los comentarios que aparecen citados de Maduro.

2. Tal vez la poca cobertura tenga relación con un suceso de suma importancia para Perú que aconteció en esos días: la suscripción de un acta para fijar las coordenadas limítrofes y geográficas con Chile (un diferendo de carácter histórico) que goza de ubicación preferencial en el cúmulo de informaciones suministradas en los días relevados 
El Tiempo emplea las palabras "diálogo", "estabilidad”, “orden democrático” y las expresiones citadas por el Secretario de Estado norteamericano, alusivas a la necesidad de una "gestión de mediación". El Comercio agrega las declaraciones del canciller ecuatoriano Ricardo Patiño, quien (en el marco de una reunión de trabajo de la Comunidad de Estados Latinoamericanos y Caribeños, CELAC) señala que en Venezuela hay condiciones para que se produzca "una mayor participación de los actores en los diálogos de paz", pero que quizás hace falta "un puente en el camino" que pueden ser los cancilleres latinoamericanos. Respecto a El Peruano, se valoriza la búsqueda de las conversaciones y las declaraciones sobre el respeto por el orden democrático en la región sudamericana.

Como afirmábamos párrafos atrás, la utilización de ciertas palabras y términos que atraviesan los discursos construidos en torno a la seguidilla de hechos acaecidos en Venezuela, no solo obliga a recordar la estructura de intereses, ideas y factores económicos que conforman el proceso de producción de la información, sino también su correspondencia en el plano de la realidad inmediata. La cobertura mediática y el espacio invertido a las cuestiones regionales ¿es un termómetro de la incidencia concreta de la integración latinoamericana en las sociedades de los Estados integrantes de la Unión?

La historia de la integración sudamericana está plagada de idas y vueltas en la conformación de proyectos que se acerquen a lo que una vez Simón Bolívar imaginó como la "Patria Grande". En las noticias, la UNASUR se privilegia en tanto proyecto integrador político para la región, como ente capaz de asumir roles de articulación y negociación en instancias de inestabilidad, turbulencia o diferendos entre naciones de América del Sur, como un hecho relevante en los últimos años. De ello, los medios regionales se hacen eco, en mayor o menor medida, pero no pueden soslayar el hecho de que existe una instancia regional antes que internacional, para la resolución de las diversas controversias. Las conclusiones preliminares parecen sugerir que el rol de los periódicos continúa siendo central para la diseminación de las noticias acerca del movimiento integracionista en la región y la información específica sobre el rol y alcances de la UNASUR. De allí que habrá que seguir observando de cerca la marcha de los procesos regionales en conjunto con las diferentes coyunturas políticas que se sucedan en el próximo año, a propósito de que se cumplirá una década de la retirada del proyecto ALCA.

\section{Fuentes consultadas}

Alaniz, M. (2012). “La integración latinoamericana en el siglo XXI”, pp. 201-208. En Vera de Flachs, M. (comp.). Manual de Historia Social Contemporánea [vol. II]. Córdoba: Báez.

Borrat, H. (1989). El periódico, actor político. Barcelona: Gustavo Gili.

El Comercio, diario (Ecuador).

_(2014a, marzo 27). "Comisión de UNASUR pide compromiso en deponer la violencia en Venezuela". Extraída el 4/III/2015 desde http://www.elcomercio.com/actualidad/mundo/ comision-de-unasur-pide-compromiso.html 
_(2014b, marzo 26). "Ricardo Patiño ve posibilidades de solución en conflicto de Venezuela”. Extraída el 4/III/2015 desde http://www.elcomercio.com/app_public.php/actualidad/ mundo/ ricardo-patino-ve-posibilidades-de.html

_(2014c, marzo 25). "María Corina Machado teme ser detenida en Venezuela". Extraída el 4/III/2015 desde http://www.elcomercio.com/actualidad/mundo/maria-corina-machadoteme-detenida.html

(2014d, marzo 25). “Detienen a tres generales por tramar 'golpe de Estado' en Venezuela”. Extraída el 4/III/2015 desde http://www.elcomercio.com/actualidad/mundo/detienena-generales-tramar-golpe.html

_(2014e, marzo 13). “Oposición venezolana insiste en cinco condiciones para dialogar con Maduro". Extraída el 4/III/2015 desde http://www.elcomercio.ec/actualidad/mundo/ oposicion-venezolana-insiste-cinco-condiciones.html

_(2014f, marzo 12). "Empezó la reunión de UNASUR para analizar situación de Venezuela”. Extraída el 4/III/2015 desde http://www.elcomercio.com/app_public.php/actualidad/ mundo/ empezo-reunion-de-unasur-analizar.html

El Peruano (2014, marzo 12). “UNASUR analizará caso Venezuela”, p. 14. Extraída el 4/ III/2015 desde http://www.elperuano.com.pe/edicion/edicion-20140312-474.aspx

El Tiempo, diario (Colombia).

_(2014a, marzo 26). "Fuerza Armada Venezolana no revela identidad de generales detenidos”. Extraída el 4/III/2015 desde http://www.eltiempo.com/archivo/documento/CMS13732336

_(2014b, marzo 25). "Maduro anuncia la detención de tres generales que pretendían 'alzarse"'. Extraída el 4/III/2015 desde http://www.eltiempo.com/mundo/latinoamerica/madurocaptura-a-tres-generales-de-aviacion-que-pretendian-alzarse/13724555

_(2014c, marzo 12). “¿Qué puede pasar en Venezuela tras un mes de protestas contra Maduro?". Extraída el 4/III/2015 desde http://www.eltiempo.com/archivo/documento/CMS13640258

_(2014d, marzo 12) “Tema de Venezuela, presente en la posesión de Bachelet”. Extraída el 4/III/2015 desde http://www.eltiempo.com/archivo/documento/CMS-13637896

_(2014e, marzo 11). "UNASUR conformará comisión para analizar situación en Venezuela”. Extraída el 4/III/2015 desde http://www.eltiempo.com/archivo/documento/CMS13634955

El Universal, diario (Venezuela).

_(2014a, marzo 27). "Comunicado de la I Reunión de la Comisión de Cancilleres de Unasur”. Extraída el 4/III/2015 desde http://www.eluniversal.com/nacional-y-politica/protestasen-venezuela/140327/comunicado-de-la-i-reunion-de-la-comision-de-cancilleres-de-unasur _(2014b, marzo 27). "Venezuela rechaza palabras de EEUU sobre la Comisión de Unasur". Extraída el 4/III/2015 desde http://www.eluniversal.com/nacional-y-politica/protestas-envenezuela/140327/venezuela-rechaza-palabras-desde-eeuu-sobre-la-comision-de-unasur _(2014c, marzo 26). "Cancilleres de UNASUR hicieron recomendaciones a Maduro". Extraída el 4/III/2015 desde http://www.eluniversal.com/nacional-y-politica/protestas-envenezuela/140 326/cancilleres-de-unasur-hicieron-recomendaciones-a-maduro 
_(2014d, marzo 26). "Declaración de los Estados Miembros de la Unasur sobre Venezuela”. Extraída el 4/III/2015 desde http://www.eluniversal.com/nacional-y-politica/protestasen-venezuela/140516/declaracion-de-los-estados-miembros-de-la-unasur-sobre-venezuela _(2014e, marzo 26). “Oposición planteó a UNASUR el tema de los derechos humanos en el país”. Extraída el 4/III/2015 desde http://www.eluniversal.com/nacional-y-politica/ protestas-en-venezuela/140326/oposicion-planteo-a-unasur-el-tema-de-los-derechos-humanos-en-el-pais

_(2014f, marzo 25). "Colombia y Paraguay piden ampliar reuniones de UNASUR en Venezuela”. Extraída el 4/III/2015 desde http://www.eluniversal.com/nacional-y-politica/protestas-en-venezuela/140325/colombia-y-paraguay-piden-ampliar-reuniones-de-unasur-envenezuela

_(2014g, marzo 12). “Unasur enviará comisión a Venezuela”. Extraída el 6/III/2015 desde http://www.eluniversal.com/nacional-y-politica/protestas-en-venezuela/140312/unasurenviara-comision-a-venezuela-imp

_(2014h, abril 7). "Maduro acepta reunirse el martes con la oposición”. Extraída el 6/ III/2015 desde http://www.eluniversal.com.mx/el-mundo/2014/maduro-acepta-reunirseel-martes-con-la-oposicion-1001608.html

Luchessi, L. (comp.) (2010). Nuevos escenarios detrás de las noticias. Buenos Aires: La Crujía.

Martini, S. (2000). Periodismo, noticia y noticiabilidad. Bogotá: Norma.

Pizarro, H. (2012). "La Unión de Naciones Sudamericanas (UNASUR)”, pp. 209-2227 En Vera de Flachs, M. (comp.). Manual de Historia Social Contemporánea [vol. II]. Córdoba: Báez.

Unión de Naciones Suramericanas, UNASUR.

_(2014a). "Tratado Constitutivo de la Unión de Naciones Suramericanas. Extraída el 4/ III/2015 desde http:/www.unasursg.org/images/descargas/DOCUMENTOS\%20CONSTITUTIVOS\%20 DE\%20UNASUR/Tratado-UNASUR-solo.pdf

_(2014b). "Reglamento General de UNASUR". Extraída el 4/III/2015 desde http://www. unasursg.org/images/descargas/DOCUMENTOS\%20CONSTITUTIVOS\%20DE\%20 UNASUR/reglamento_gral.pdf

_(2014c). "Protocolo adicional al Tratado Constitutivo de UNASUR sobre Compromiso con la democracia". Extraída el 4/III/2015 desde http:/www.unasursg.org/images/descargas/ DOCUMENTOS\%20CONSTITUTIVOS\%20DE\%20UNASUR/Protocolo-Adicional-al-Tratado-Constitutivo-de-UNASUR-sobre-Compromiso-con-la-Democracia-opt.pdf 